\title{
Research on Tourism Development Based on the Religions Cultures of China's Ethnic Minorities -- A Case Study of the Flora Worship of the Yi Ethnic Groups in Northwest Guizhou
}

\author{
Xiang Gao', a \\ ${ }^{1}$ Institute of Taoism and Religious Cultures, \\ Sichuan University, Chengdu,Sichuan Province, China \\ a488897525@qq.com
}

Keywords: Traditional religious cultures; Tourism development; Flora Worship

\begin{abstract}
As an important part of traditional culture of minority nationalities, traditional religious culture is an important resource for economic and social development of ethnic minority areas. The development of tourism based on the traditional religious cultures in ethnic minority regions is not only the need of our times, but also an important way to promote the healthy development of the religious cultures of ethnic groups. Based on the example of the flora worshiping ritual among Yi people in northwest Guizhou, this essay will point out what practical problems can by solved by developing cultural tourism based by traditional ethnic religions and analyze the internal and external environmental factors affecting cultural tourism. It will further expound on the approaches to developing cultural tourism.
\end{abstract}

\section{Introduction}

As a kind of economic industry, tourism is a mode as well as a means of poverty alleviation in ethnic minority area, while the achievement of its economic benefits solely depends on the unique cultures of the ethnic groups. As a cultural phenomenon, religions of ethnic minority groups have accumulated rich cultural resources in the course of their development and are also an important resource for the economic and social development of ethnic minority areas. The development of traditional religious culture tourism in minority areas is a very effective way to alleviate poverty in minority areas. Being a "teaching-how-to-fish" way of poverty alleviation, traditional religious cultural tourism aims to promote cultural development and is also conducive to the development of local economy by giving impetus to local infrastructure construction and the development of the secondary and tertiary industries, as other tourism activities can do. In order to play a positive role in promoting cultural tourism in minority nationalities areas, we must consider the following questions: How to develop minority religious cultures? How to play an active role in cultural tourism development based on minority religions? This approach is not only in accordance with the requirements of the development of the times, but also is an important way to promote the orderly and healthy development of the traditional cultures of ethnic groups. This paper, taking the field investigation of the ceremony of "flora worshiping" in northwest Guizhou province as an example, will look into the above questions.

\section{Cultural Tourism based on Ethnic Minority Religions}

Cultural tourism refers to the tourism activity in which tourists consume mainly cultural tourism products, experience and enjoy the cultural connotation during its course.[1] Minority religious cultural tourism, as a business activity, is based on the traditional religious cultures of minority groups to provide cultural tourism products to meet the market need, to promote minority religious cultures, to exhibit the cultural connotations of traditional religious cultures and at the same time fulfill the purpose of traditional minority religions as a means to enlighten, to arouse the moral responsibility, and to reshape values. The consumption of tourism products is essentially a cultural consumption, a realization of the value of service through the consumption of culture, as well as the 
achievement of economic benefits for tourism operators. Therefore, the development of ethnic religious cultures is beneficial not only to the protection and inheritance of traditional religious cultures of ethnic minorities, but also to the promotion of coordinated development of economy and society in ethnic minority areas.

\section{The Yi People's Flora Worshiping Ritual in the Bali National Forest Park of Azalea in Northwest Guizhou}

The "Baili Azalea" scenic spot (The National Forest Park of Azalea) in northwest Guizhou is one of the national 5A-class tourist attractions and a national Eco-tourism demonstration zone because of its rich variety of azaleas and the wide area of rhododendron forest. This area is inhabited by Yi people, and the traditional culture of the Yi nationality is abundant. In the long period of their social life and practice, the Yi people in northwest Guizhou have formed their own unique belief system. In their worship of natural things, they have developed the concept of animism and the practice of nature worship and ancestor worship, characterized by offering various sacrifices. As Professor Zhang Zehong explains in his Cultural Communications and Ritual Symbolism: A Comparative Study of Religious and Taoist Sacrificial Rites in Southwest China, "faith is a belief in the existence of nature, society and individuals, and rituals are acts of expressing and practicing these beliefs".[2]

The Yi people's most favorite big red azalea flowers, called "som flower" or "or "rhododendron delavayi", are considered as the "holy flower" of the Yi tribes. There are rituals associated with som flowers, indicating how significant azalea worship is among the Yi people. The local Yi tribes will hold annually a grand and ancient ritual of "flora worshiping" during the second lunar month, when Azaleas are blooming.

One day before the ritual, Bumos will go to the worship spot to make necessary preparations, gathering and processing the natural ritual items such as paulownia branches, five colored soil, bamboo leaves and holly leaves as well as putting up the alter, which is called Chashenzuo. Chashenzuo, or the alter is a unique Yi ritual scene. Depending on the ritual requirements, paulownia crotches of different lengths would be removed partly or wholly of barks, decorated with bamboo leaves, five color soil and couch grass. The whole ritual will be performed within the area of Chashenzuo. An atmosphere of solemnity and reverence prevails the ceremony, with nearly 2,000 participants attending. The whole ritual consists of four parts: toasting, narrating stories about flowers, worship flower gods, and praying for and accepting blessings.

American anthropologist Clifford Geertz writes in his The Interpretation of Cultures, "any cultural event not only exists but also has meaning and occurs because of this meaning, and the ritual of cultural events is no exception".[3] As a traditional religious ritual, the ceremony of flora worship features a long preparation process, a large number of participants and a grand scale. The whole ritual includes four parts: toasting, narrating the stories of flowers, worshiping the flower gods, praying for and receiving blessings, fully demonstrating the unique charm of the traditional religious culture of the Yi nationality. Traditional, unique religious artifacts with Yi ethnic characteristics are often used and Bumos, as the communicator between humans and gods, play an important role in the ritual. With myths and legends, the ancient Yi scriptures, the ancient Yi language spoken by Bumos, the traditional Yi dances and the sacrifices offered, the flora worshiping ceremony expresses the Yi people's deep respect to their ancestors and is nothing but mysterious and rich in religious culture. Its cultural implications are mainly reflected in the following: the ceremony is not held for the sake of a certain person or a certain group of people to get salvation or become immortal. The ritual embodies the concept of animism, expressing the Yi people's longing for happiness and their prayer for good crops and peace in the coming year.

\section{The Significance of the Ecological Concepts Represented in the Flora-worshiping Rituals to Tourism Development}

The flora-worshiping ritual symbolizes the efforts made by the ancestors of the Yi people to control the environment by offering sacrifices to please nature. It contains a wealth of Eco-philosophical 
ideas that human beings can coexist in a harmonious way.

The Idea of Animism. The civilization of the Yi people in northwestern Guizhou belonged to the agricultural civilization and its production activities heavily depended on nature. Natural powers were envisioned or fashioned into supernatural gods who could shelter and protect human beings. At the same time religious rituals, performed to please the supernatural gods, satisfied the need of people and were able to persist and spread. By offering sacrifices to azalea flower gods, people believed that azalea flowers would bloom and bring material comfort to the people in the Yi tribe areas. They deified nature and azalea flowers, developing an azalea worship and a set of azalea-related taboos. In this way an ecological ethic was formed to hold nature in awe and reverence.

Taboo-based Religious Concept. In accordance with the animistic view that all things have souls, people revere and respect nature, which has led to the general religious customs characterized by taboos and constraints. The relationship between human beings and nature is adjusted in this way. Holding religious ceremonies enables the Yi people to believe in the existence of natural gods and give them enough respect, to be aware of the importance of azaleas to their life. While the ecological ethics expressed by the religious rituals are not clearly specified or stated, they have very strong binding force on people's behaviors. The religious taboos based on supernatural powers become the moral constraints regulating the local Yi people's behaviors. For thousands of years, these constraints and religious taboos have helped protect the environment of hundreds of acres of azalea forests in this area. This has perfectly demonstrated the fact that the ecological ethics "reflected in the ancient natural religions and folk religions can help protect both the azalea forests and ecological environment".

The Idea of Harmony between Human Beings and Nature. The living conditions of the Yi minority regions in northwestern Guizhou is relatively tough, with most of the region belonging to karst landforms and with large areas covered by rocky mountains. Farmland and forests, the resources essential for people's livelihood, are inadequate and even scarce. This kind of environment forces people to carry out productive activities is with what they have been given by nature. Productive activities are carried out in nature and are inseparable from certain natural environment. The Yi ancestors regulated people's behavior in various ways, making them aware of the proper way to protect the forest, and how to achieve the sustainable utilization of forest resources. They loved and protected nature, in much the same way they loved and protected their lives. They gradually formed a series of religious and secular taboos, and customary laws related to environment protection. The Yi people believe that over-exploitation of resources by human beings will lead to punishments by nature. They adjust their culture in accordance with the environmental changes and the development of the times, forming a harmonious ecological view that it is important for human beings to adapt to their environment.

\section{Practical Problems that can be Solved by Developing Traditional Religion-Based Cultural Tourism in Ethnic Minority Regions}

Increase in Income of Religious Workers. The person who presides over the religious ritual among the Yi tribes in northwestern Guizhou is Bumo. "Bu" means chanting scriptures while "mo" is an elderly of wisdom. Together, Bumo means "an elderly priest chanting scriptures and performing sacrificial ceremonies". Presiding over the religious ceremony, often well versed in and possessing Yi scriptures, Bumo is the knowledge disseminator who hands down traditional cultures and who occupies a special position in the Yi communities. Performing various kinds of sacrificial and funeral rites to make a living, professional Bumos used to get decent incomes. But with the development of cultural diversity and religious openness, there has been a reduced demand for the service of priests in the the Yi people-inhabited areas in northwest Guizhou, which has in turn resulted in the decrease of income for the Bumos. The various sacrificial rituals from traditional Yi religious culture, now performed as a part of tourism-promotion endeavor, will inevitably bring refreshed attention to the Bumo group, who, as the leading part in performing the rituals, will get a higher income. 
Improvements in Infrastructure to be Brought by the Development of Religious Sacrificial Ceremonies. Tourism is a kind of trans-space consumption activity, so transportation facilities are necessary for tourism development. To develop tourism in ethnic minority areas requires accessible or easy local transportation. By taking advantage of the geographic location of the Baili National Forest Park of Azalea, the transportation in the selected ritual performing spots can be further developed to ensure easy access, convenient moving and easy exit. Convenient transport will promote tourist consumption and ultimately boost tourism and the local economic development in this area, helping lift the local people out of poverty. Besides convenient transportation, other public service facilities are also indispensable for the cultural tourism development in minority-inhabited areas. Developing tourism requires coordinated efforts from other relevant industries, including restaurants, hotels, environmental management, etc. The development of traditional cultural tourism in ethnic minorities regions cannot be achieved without the support from other related industries and their development will improve the living standards of people in the Yi ethnic region.

The Economic Benefits to be Brought by Environmental Protection Awareness and Ecological Conception in Religious Cultures. Enjoying preferential policies, minority-populated areas can be helped out of poverty and even live a wealthy life by developing tourism. The over-exploitation of tourism resources, however, will lead to irreversible side effects and the development of tourism in many areas cannot be sustained. In the traditional culture of the Yi people, the worship of nature ensures people's great enthusiasm for environmental protection. The earliest humans wanted to control the environment by praying. For lack of tools and other means of protection and strength, they were at the mercy of the environment. They assumed that the surrounding environment was controlled by a number of hidden forces and supernatural entities that could be influenced by religious rituals or their dedication to these forces and entities. This strategy was represented by myths, rituals, and superstitions in ancient times. The ceremonies in Yi people's religious belief system contains the simple values that the Yi people's ancestors coexisted harmoniously with a tough natural environment and that all things have souls: there is a mountain god in the mountain, a flower god or goddess in a flower and a tree god in a tree. As a result, they perform sacrificial rituals each year to mountains, water, trees, flowers and other natural objects closely-related to their daily life. They have developed a whole system of belief and an understanding that all forces are balanced. This simple, harmonious ecological concept plays an important role in the protection of the local ecological environment, which directly leads to an ecological wealth for the local people and the maximum preservation of the world's most complete thyme rhododendron forest. This in turn will attract more tourists to this region and thereby give impetus to the economic development in the minority area.

The Actual Promotion of Economic Interests. From an economic point of view, the diversity of minority cultures is a unique resource for developing tourism industry and has incomparable advantages over other industries. Especially now under the situation that the nation is vigorously promoting the development of cultural industries, ethnic minority areas should seize this strategic opportunity to actively tap the potential advantages of cultures and promote the transformation of cultural industries into productive forces. Therefore, tourism economy will become the mainstream pillar industry in the industrial chain of minority regions and will make great contributions to the development of the local economy and society in the future economic structure. As tourism developers, we should enhance performance and participation and activate the vitality of tourist destinations in the development of minority religious tourism culture. Pure tourism destinations aremainly composed of static landscapes, thevitality of whichcannot be fully demonstrated without the contrast ofdynamic landscapes. So it is necessary to employ actitivies that canenable thetourists to participatein, to enjoy and experience religious cultures. This would offer tourists the opportunity to broaden theirhorizons and enrich their knowledge.

Religious activities with distinctive local characteristics and high cultural quality can satisfy tourists. Rich performances and visitors' participation have injected vitality into the quiet landscape of the tourist destination, which has added to an elegant taste appealing to the tourists while they are enjoying the quiet sceneries. This scenario will attract more tourists, thereby increasing economic 
income in ethnic minority areas .

\section{The Internal and External Environment for Developing Tourism Based on the Yi religious Culture}

Religious tourism based on thnic minority cultures is different from the general tourism of sightseeing or adventures: psychologically it stirs a sense of curiosity in the tourists, who become both adventurers exploring an "other" culture and travelers who pursue pleasure in body and mind. With increasing urbanization, people feel more stress in their lives and would enjoy travelling to relax themselves. Of course, in the course of developing religious cultural tourism, it is necessary to build an internal and external environment fit for the development. This strategy should be government dominated and benefit oriented.

Cultural Environment. "Culture" is simply "humanizing". Culture can transcend race, region and language and is a shared cultural heritage of all the people in the world. Each culture has its own unique set values, distinguishing one nationality from another. This uniqueness is an important element to arouse tourists' curiosity. The traditional religious culture of the Yi tribes is a deeply-rooted spiritual belief formed in the long process of its development and is the common psychological identity of the Yi people. With the development of religious cultural tourism, the influx of tourists, however, will inevitably bring some foreign cultures to gradually influence the traditional spiritual belief. On the one hand, the traditional culture of the Yi nationality has become more colorful by absorbing foreign cultures. For example, flora worshipping rituals have been much influenced by Taoist culture and a lot of modern elements have found their way into the ceremonies to attract tourists. On the other hand, the relatively weak part of the minority culture has gradually faded under the influence of foreign cultures, which leads to the incompleteness of traditional religious culture. The traditional flora shipping, for example, was to offer sacrifice to the nonhuman azalea flowers, but in the process of tourism development, a statue of Somawei has been erected to give tourists a sensual perception. So now many visitors believe that "flora" is a person. In the development of Yi people's religious culture industry, therefore, we should have a clear understanding of this situation and should help build up the Yi people's self-confidence in their own culture. Appropriate policies to inherit and develop minority groups' cultures can help us reject the bad in traditional minority cultures. At the same time, it is necessary to be cautious about foreign cultures, making sure that only the good part is accepted and absorbed.

Human Talents Environment. With the development of society, especially in the face of "invasion" of foreign cultures, how can the traditional religious culture of Yi people constantly enhance the Yi culture and maintain its confidence? I believe that the key is talented people and here the talented people in the Yi traditional culture are Bumos. "Bu" means chanting scriptures while "mo" is an elderly of wisdom. Together, Bumo means "an elderly priest chanting scriptures and performing sacrificial ceremonies", who occupy a special position in the Yi communities. In ancient times, the political structure of $\mathrm{Zi}$, Mo and Bo, the $\mathrm{Zi}$ class, Mo class and Bo class all enjoyed considerably high political and economic status. Ranking the third in this social-political structure, Bumos were important decision-makers in the tribes and symbolized power, higher social status, and wealth. In other words, Bumos were regarded as the "encyclopedia" of the Yi society and the inheritors of traditional Yi culture. Presiding over the religious ceremonies, well versed in and possessing Yi scriptures, Bumos are the knowledge disseminators in the Yi society and also have wide influence on the secular life of the Yi people. They are considered as the special people who connect humans and gods, serve as the media between them. They lead social and religious rituals. As the disseminators, inheritors and performers of traditional Yi culture, Bumos are at the core of traditional Yi culture. It is no exaggeration to say that if Bumos were disappearing, the traditional religious culture would lose its driving force in its development. Therefore, for the industrial development of traditional Yi religious culture, the government must pay attention to the foresting of Bumos and lay down policies to attract more young people to learn and study Bumo culture, to guarantee the cultural inheritance of Yi religion and cultivate more talents for the development of Yi people's religious culture industry. 
Benefit Assessments. The Yi ethnic people have a long history and a rich traditional culture. They believe that all things have souls and have formed a belief system that worships mountains, water, wind, thunder and flowers. The Yi people practiced nature worship and have developed a complete set of ecological protection values in the traditional Yi society. For example, one should not destroy the forest, or he will incur punishment from god. Such belief and practice help ensure the protection of vegetation and preserve the sound eco-system, which in turn attracts more tourists to visit. Therefore, the traditional Yi religious culture can not only help protect the local ecological environment, attract more tourists by spreading its religious culture, and improve the economic benefits in the area; it can also help ensure the inheritance of traditional Yi religious culture, strengthen the social integration within the Yi communities and protect the local ecological environment.

The Principles of Religious Tourism Resources Development. Because ethnic minority religious tourism has distinctive features and various tourism values, it has attracted great attention in the development of tourism today. While the religious tourism resources of ethnic minorities are a kind of unique cultural tourism resources, which has not only all the characteristics of cultural tourism resources, but also unique ethnic characteristics and distinctive religious characteristics. The following principles must be observed in its development: First, It is critical that a scientific attitude should be taken when we look at religious events and religious issues, both historically and contemporarily. The development of religion cultural tourism should comply with the relevant regulations of the state and the religious laws, keep away from illegal, pseudo-religious and superstitious elements. The development of religious cultural tourism should follow scientific procedures and employ scientific methods in the analysis, demonstration and construction of the tourism programs. To adhere to the scientific attitude and comply with the relevant regulations of the state and the religious tenets, to prevent the penetration of illegal, pseudo-religious and superstitious elements in the name of religious tourism resources development, the whole development work should follow scientific procedures and use scientific methods for analysis, demonstration and construction. Second, Historical Principle. Minority religious tourism resources have historical and cultural heritages and precious cultural wealth. As for the form, structure, material, style, color and so on, the historically original appearance shouldn't be changed as far as possible. It should be noted that lack of authenticity or even making up something that did not happen in history would undermine the long-term development of cultural tourism, not undermine the long-term development; The development work should not destroy the religious culture formed in the long history, and pay attention to the excavation and display of the historical, cultural and artistic connotations of religious tourism resources, so as to enhance their cultural quality. Three, Benefit Principle. Ethnic minority religious tourism should pursue economic benefits and pay more attention to social and environmental benefits, having a proper market survey and analysis of religious tourism. It should not develop blindly according to "tourist attraction in imagination". Meanwhile, the excellent religious culture and superb religious art should be mainly demonstrated. Four, Personality Principle. A distinctive personality is the source and soul of tourism landscapes. To avoid weakening the attraction as the results of the repetition and boredom, we should fully display the geographical features of the resources and the ethnic and folk cultural characteristics based on the Yi nationality's culture.

\section{Strategies of and Approaches to Developing Minority Religion-Based Cultural Tourism}

\section{The Development of Traditional Religious Tourism should Ensure the Authenticity of}

Religious Rituals. In the rapid economic development of today, the pursuit of economic interests is bound to accelerate the commercialization of traditional culture. At the same time, in order to satisfy the curiosity of tourists, traditional religious culture will gradually lose its pureness or even its essence. For example, something else may be added when presenting religious culture to tourists. Sometimes the presentation of culture or the demonstration of the rituals may be distorted, blurring the distinction between essence and dross or even deliberately emphasizing the backwardness and primitiveness of the culture. As an industry, cultural tourism based on ethnic minority religions has 
at its core the integrity of the religious culture and depends on its uniqueness and local features as its soul. The real and authentic experience of the minority religion will bring tourists spiritual enjoyment or shock, which is the very reason why tourists swarm into this area off azalea-viewing seasons. Therefore, the traditional religious culture of ethnic minorities cannot afford to lose its original cultural connotation in the ceremony just to specially satisfy the curiosity of tourists. According to my investigation, the current flora worshipping rituals at the Baili National Forest Park of Azalea have two forms. The one performed at Jin Po scenic spot is more traditional and original, and lasts for about an hour. The second one is a simplified ceremony, keeping the cream of the flora worshipping ritual and focusing on its entertainment function. The "flora worshipping" ceremony is in essence a religion for the Yi people. If focused on only the performing effect, the traditional ceremony will be modified and be added to it some elements from foreign cultures. This will lead to the distortion of the "ceremony" and mislead tourists or the audience. Therefore, in performing the ceremony of flora worshipping, it is important to ensure its originality, keep as much of its original flavor as possible. Only in this way can it attract more tourists.

A Cultural Tourism Zone can be Built by Integrating other Traditional Religious Cultures such as Fire Worshipping and Mountain Worshipping. Despite the fact that Baili National Forest Park of Azalea attracts large number of tourists every year, my investigation still reveals some problems. Tourists swarm into this area during the azalea blooming season, which is between March and May, the flowering period of azaleas. The rest of the year becomes the off-season with few tourists visiting. It can be seen that the "golden time" of the scenic spot is too short. Therefore, to further expand the "golden season" of tourism, new resources must be developed to attract tourists. In my opinion, the scenic spot can rely on its good natural ecological environment and unique cultural ecological system to develop a series of traditional Yi religion-related cultural activities, such as mountain-worshiping, fire-worshiping and water-worshiping rituals. A cultural zone or area can be developed based on the various traditional Yi religious activities, each month featuring a specific ritual. In this way, tourists will be attracted to come during the off-season, and long-term economic benefits can be guaranteed. At the same time, the traditional culture of $\mathrm{Yi}$ people will be preserved and inherited from generation to generation.

Tourists can be Offered the Opportunities to Experience Religious Cultures. Religious rituals are both ideologically and behaviorally full of symbolism, which happens to be where tourists are most interested. The development of traditional religious culture tourism should take into consideration the psychological needs of tourists and make tourist experience a part of the whole strategy. In the process of the ceremony, for example, tourists can be invited to experience the complete ritual activities. They are no longer mere by-standers; they are participants in the rituals. In this way, they can vividly feel the religious concept of the Yi people's traditional culture. At the "flora worshiping" ceremony, sacrifices are often offered to assuage gods' fury or please gods. After the ceremony, in accordance with the tradition, the sacrificial animals are often cooked and shared by people participating in the ceremony. The food, believed to have supernatural powers through the flora worshiping ritual, has gained a kind of holiness or sacredness. By enjoying the sacrifice, people also gain the power or strength of gods and can have good luck ever since. So an appropriate link can be designed to enable tourists to participate in and experience the rituals. They will be part of the sacrifice offering and food sharing. In this way the tourists will gain religious experience while the local Yi people will gain the economic benefits.

\section{Conclusion}

As an important carrier of Yi people's traditional religious culture, the ritual of flora worshiping in northwest Guizhou contains rich religious and cultural concepts, and, if developed in an appropriate way, can not only realize the transmission and protection of the Yi people's traditional religious culture, but also can promote the harmonious economic and social development in this area. 


\section{References}

[1]Song Ziqian, Tourism Integration and development, Beijing: China travel press, 2015, p.145.

[2]Zhang Zehong, Cultural Communications and Ritual Symbolism: A Comparative Study of Religious and Taoist Sacrificial Rites in Southwest China, Chengdu: Bashu Publishing House, 2008, p.1.

[3]Clifford gertz, The Interpretation of Cultures, translated by Han Li, Nanjing: Yilin Publisher, 1999, p. 131. 